\title{
Uma análise multicritério de alternativas para o tratamento de resíduos sólidos urbanos do município de Juazeiro do Norte no Ceará
}

\author{
A multi-criteria analysis of alternatives for the treatment of municipal solid \\ waste in the municipality of Juazeiro do Norte Ceará
}

\author{
Luiz Neto Paiva e Silva Müller'* $\odot$, João Bosco Furtado Arruda², \\ Rosane Lucia Chicarelli Alcantara' ${ }^{\circledR}$, Rafaela Lourençano Pereira' ${ }^{\circledR}$
}

\section{RESUMO}

Gestores públicos necessitam planejar e implementar alternativas sustentáveis de gestão de Resíduos Sólidos Urbanos (RSU) que contenham unidades de tratamento de resíduos. Entretanto, a seleção de alternativas de tratamento de resíduos é um processo complexo, sendo necessário considerar diferentes critérios. Nesse sentido, este artigo tem o objetivo de analisar diferentes alternativas de tratamento de RSU para o município de Juazeiro do Norte no Ceará, Brasil, por meio da avaliação dos critérios econômico, ambiental, social, técnico e regulatório. Para alcançar esse objetivo, aplicou-se o método multicritério de apoio à decisão Analytic Hierarchy Process (AHP), com o auxilio de diversas técnicas quantitativas de projeção e de dados coletados em campo e em fontes secundárias. Os resultados mostram que as alternativas 1 (centro de triagem manual e unidade de compostagem descentralizados) e 3 (centro de triagem manual e biodigestor descentralizados) são as opções de tratamento de RSU mais favoráveis para o município, com percentual de 25,11 e $24,97 \%$, respectivamente. As alternativas descentralizadas (1 e 3) levam vantagem sobre as centralizadas 2 (centro de triagem automatizado e unidade centralizada de compostagem), 4 (centro de triagem automatizado e biodigestor centralizado) e 5 (centro de triagem automatizado e incinerador) em virtude, principalmente, da maior geração de empregos e viabilidade técnica. Entretanto, com a realização da análise de sensibilidade em uma avaliação na qual o critério econômico tinha peso superior ou igual a 70\%, constatou-se que o resultado geral mudaria e as alternativas centralizadas 2 e 4, com melhores resultados econômicos, seriam apontadas como as melhores opções.

Palavras-chave: tratamento de resíduos; método multicritério de apoio à decisão; processo analítico hierárquico.

\begin{abstract}
Worldwide, public managers need to plan and implement sustainable alternatives for the management of Municipal Solid Waste (MSW) that consider waste treatment plants. However, the selection of waste treatment alternatives is a complex process which must consider different criteria. In this sense, the present article had the objective of analyzing different MSW treatment alternatives for the municipality of Juazeiro do Norte in Ceará, Brazil, through the evaluation of economic, environmental, social, technical, and regulatory criteria. The Multicriteria Decision Making Method AHP (Analytic Hierarchy Process) was applied, supported by several quantitative techniques of projection and data collected in the field and in secondary sources. The results show that alternatives 1 (decentralized manual sorting center and composting units) and 3 (decentralized manual sorting center and anaerobic digesters) are the most favorable MSW treatment options for Juazeiro do Norte, with a percentage of 25,11 and $24,97 \%$, respectively. The decentralized alternatives 1 and 3 have an advantage over the centralized alternatives 2 (automated sorting center and centralized composting unit), 4 (automated sorting center and centralized biodigester) and 5 (automated sorting center and incinerator) due, mainly, to the greater generation of jobs and technical feasibility. However, sensitivity analyzes enhances that, in an evaluation in which the economic criteria had a weight greater than or equal to $70 \%$, the overall result would change significantly and the centralized alternatives 2 and 4, alternatives with better economic results, would be considered as the best MSW treatment options.
\end{abstract}

Keywords: waste treatment; multicriteria decision making method; analytic hierarchy process.

'Universidade Federal de São Carlos - São Carlos (SP), Brasil.

2Universidade Federal do Ceará - Fortaleza (CE), Brasil.

*Autor correspondente: luizpsmuller@gmail.com

Conflitos de interesse: os autores declaram não haver conflitos de interesse

Financiamento: nenhum.

Recebido: 06/05/2019 - Aceito: 25/11/2019 - Reg. ABES: 20190143 


\section{INTRODUÇÃO}

A gestão de resíduos sólidos urbanos (RSU) é um processo complexo, composto de diversas etapas, como coleta, transporte, tratamento e disposição final de resíduos. Além disso, o aumento populacional e a rápida urbanização das cidades potencializam as dificuldades enfrentadas pelos gestores municipais na busca por uma gestão adequada dos RSU (KHAN et al., 2016).

Entre as diversas opções existentes, a simples disposição final dos RSU em aterros ou lixões é uma alternativa comumente usada em diversas regiões no mundo, principalmente nos países em desenvolvimento (BEHROOZNIA et al., 2018). Entretanto, gestores públicos necessitam planejar e implementar alternativas de gestão de resíduos mais sustentáveis (KHAN et al., 2016). No decorrer dos anos, constatou-se a existência de inúmeras desvantagens ambientais e socioeconômicas relacionadas aos aterros e lixões. Pesquisas apontam que resíduos dispostos sem tratamento em aterros ou lixões contribuem significativamente para a intensificação do efeito estufa, da poluição do ar, da poluição das águas e dos problemas de saúde pública (THAKUR; GANGULY; DHULIA, 2018; YANG et al., 2018).

Nesse sentido, a implementação de unidades de tratamento (mecânico, biológico e/ou térmico) de resíduos apresenta-se como opção mais sustentável em relação à simples disposição dos resíduos em aterros ou lixões. Além da disposição final nesses locais, os RSU podem ser direcionados a unidades para a realização de tratamentos como triagem e reciclagem, compostagem, digestão anaeróbica com geração de biogás e incineração (MIA et al., 2018). Esses e outros tratamentos mecânicos, biológicos e térmicos podem ser usados separadamente ou em soluções agregadas, com o intuito de recuperar resíduos recicláveis, extrair energia ou alterar certas características dos resíduos, como volume e nível de contaminantes (CHRISTENSEN, 2011).

No entanto, antes de se proporem e implementarem mudanças no sistema de gestão de resíduos sólidos (RS), Chang e Pires (2015) sugerem a utilização de algum método de apoio à decisão. Na literatura, é possível levantar diversos estudos que utilizam métodos desse tipo no planejamento de sistemas de gestão de resíduos, de forma a avaliar e comparar diferentes alternativas (MERSONI; REICHERT, 2017; REICHERT; MENDES, 2014; SOLTANI et al., 2015; YAP; NIXON, 2015). A seleção de alternativas de tratamento de resíduos é um processo complexo, em que se devem considerar diferentes critérios de avaliação, como o social, o ambiental e o econômico (QAZI; ABUSHAMMALA; AZAM, 2018). Nesse sentido, os métodos multicritérios de apoio à decisão possuem destaque em trabalhos da área.

Diante disso, este artigo tem o objetivo de analisar diferentes alternativas de tratamento de RSU para o município de Juazeiro do Norte, no Ceará, por meio da avaliação e comparação dos critérios econômico, ambiental, social, técnico e regulatório. Para alcançar esse objetivo, aplicou-se o método multicritério de apoio à decisão (MMAD) analytic hierarchy process (AHP), com o auxílio de diversas técnicas quantitativas de projeção e de dados coletados em campo e em fontes secundárias.

\section{Alternativas de tratamento de resíduos sólidos urbanos}

Alternativas de tratamento de RSU - como unidades de triagem, de compostagem e de digestão anaeróbica - podem ser planejadas e implementadas separadamente ou em soluções agregadas, seguindo o modelo centralizado ou descentralizado. As alternativas de modelo centralizado possuem estruturas com grande capacidade de processamento de resíduos, alto grau de tecnologia e automatização (menos mão de obra), situam-se em áreas geográficas específicas e são controladas por uma grande estrutura corporativa. Esse modelo consegue reduzir os custos por tonelada de RS, entretanto necessita de elevado investimento inicial e, por esse motivo, é mais comum em países e regiões de renda mais elevada (CHANG; PIRES, 2015).

Em contrapartida, Chang e Pires (2015) afirmam que as alternativas de modelo descentralizado caracterizam-se por unidades locais com processos de baixa escala de processamento de resíduos, que utilizam pouca tecnologia e automatização, necessitando de maior número de pessoas trabalhando. Esse modelo é mais frequentemente usado em países e regiões de baixa e média renda, por seu menor nível de complexidade e menor necessidade de investimento. No entanto, o custo por tonelada tratada é geralmente maior, porque as unidades possuem baixa escala de RS e elevado custo de mão de obra.

A seguir, são expostas as principais características das unidades de triagem, compostagem, digestão anaeróbica e incineração.

\section{Unidade de triagem de resíduos sólidos (tratamento mecânico)}

Segundo Chang e Pires (2015), o tratamento mecânico ajuda na obtenção de melhores resultados na gestão de RS. Os processos ocorrem em unidades de triagem (manuais ou automatizadas), onde acontecem as atividades de separação, limpeza e acondicionamento, por tipo de material, para posterior utilização ou venda (FADE, 2014). Ao analisar a ordem de prioridade da Política Nacional de Resíduos Sólidos (PNRS) (BRASIL, 2010), vê-se que o tratamento mecânico segue essa ordem de forma efetiva. Um dos principais objetivos da PNRS é o incentivo à indústria da reciclagem (quarto nível de prioridade) e a triagem dos RSU é essencial para efetivá-lo.

A Fundação de Apoio ao Desenvolvimento da Universidade Federal de Pernambuco (FADE, 2014) cita que os custos de implantação, operação e manutenção de unidades de triagem variam consideravelmente em relação ao número de habitantes do município. Para uma população entre 10 e 30 mil habitantes, estima-se o valor de 502,5 R \$/t. Já para uma população entre 250 mil e 1 milhão de habitantes, o valor estimado é de 179,5 R\$/t (FADE, 2014). Em relação à geração de receita, o material reciclável, principal produto dos centros de triagem, possui grande valor econômico e é vendido de acordo com o mercado da região.

No contexto ambiental, a reciclagem de materiais dos RSU provenientes de centros de triagem possui um papel ambiental importante na redução da quantidade de RS que vai para o aterro (CHESTER; MARTIN; SATHAYE, 2008) e na diminuição da emissão de gases de efeito estufa (GEE) (KING; GUTBERLET, 2013). Segundo a FADE (2014), a emissão de GEE mitigada pode ser mensurada pela quantidade de RS que se evita depositar em aterro.

Os centros de triagem automatizados geram, aproximadamente, 10 empregos para cada 10 mil toneladas anuais de RSU tratados (ILSR, 1997). Por outro lado, em centros de triagem manual, o Ministério das Cidades (BRASIL, 2008) indica aproximadamente 50 trabalhadores para cada 10 mil toneladas por ano.

De acordo com Chang e Pires (2015), a tecnologia utilizada no tratamento mecânico é mundialmente popularizada e madura, especialmente na Europa Ocidental e em alguns países da Ásia. Em comparação com outros tipos de tratamento, a viabilidade é alta, há baixo risco de falta de conhecimento técnico e pouca necessidade de mão de obra especializada, principalmente em centros de triagem manual, sendo a triagem automatizada um pouco menos viável. 


\section{Unidade de compostagem (tratamento biológico)}

A compostagem é o tratamento biológico da matéria orgânica realizado por meio de um processo aeróbico (na presença de oxigênio), que resulta no composto ou fertilizante como produto final (ABBASI; RAMASAMY, 1999). A compostagem segue a ordem de prioridade da PNRS (BRASIL, 2010), evitando a disposição final de resíduos com possibilidade de tratamento.

As unidades de compostagem para populações entre 10 e 30 mil habitantes possuem custo unitário de investimento e de operação e manutenção de $\mathrm{R} \$$ 86/t, em contrapartida as unidades para populações entre 250 mil e 1 milhão de habitantes possuem custo de $\mathrm{R} \$ 84,3 / \mathrm{t}$ (FADE, 2014). Em relação à receita, segundo o Compromisso Empresarial para Reciclagem (CEMPRE, 2016), o produto da compostagem pode ser vendido por preços entre $\mathrm{R} \$ 100$ e 150 por tonelada. A World Wide Fund for Nature Brasil (WWF Brasil, 2015) cita que $100 \mathrm{~kg}$ de resíduos orgânicos geram de 30 a $40 \mathrm{~kg}$ de composto.

Destacam-se, também, os benefícios ambientais das unidades de compostagem. De acordo com Inácio, Bettio e Miller (2010), a metodologia Avoidance of Methane Emissions Through Composting (AMS.III.F) estima que a compostagem gera 10 vezes menos gás metano do que o aterro. Para o cálculo de produção de metano na compostagem, a metodologia AMS.III.F usa os valores de 4 e $10 \mathrm{~kg}$ de gás metano para cada tonelada de resíduo tratado, na base úmida e na base seca, respectivamente. O gás carbônico não é gerado nesse tratamento. Ademais, ele gera a diminuição da quantidade de resíduos dispostos em aterro (100\% do resíduo orgânico tratado). Segundo o Guia para a Compostagem criado pela WWF Brasil (2015), o tratamento de compostagem transforma todo o RS orgânico em composto, calor, água e gases.

Em relação ao âmbito social, estudo realizado pelo Institute For Local SelfReliance (ILSR, 1997) aponta que as unidades de compostagem com operação mecanizada geram em torno de quatro empregos para cada 10 mil toneladas anuais de resíduos orgânicos tratados, número quatro vezes maior do que a quantidade de empregos criada em aterros. Em relação às unidades com operação manual, a WWF Brasil (2015) define a necessidade de seis trabalhadores para cada 4,38 mil toneladas anuais de resíduos, ou seja, 14 empregos para cada 10 mil toneladas, 3,5 vezes mais que as unidades mecanizadas.

O Centro de Apoio Operacional às Promotorias de Proteção ao Meio Ambiente (CAOPMA, 2013) afirma que a compostagem, comparada com outros tipos de tratamento de RSU, é uma técnica já consolidada e que possui grande simplicidade e praticidade em seus processos, o que exige pouca especialização da mão de obra. Entretanto, ao longo dos anos, no Brasil e em vários países de baixa renda, as usinas de compostagem de modelo centralizado não foram bem-sucedidas, sendo os baixos índices de coleta seletiva um dos principais motivos (ALI, 2004; FEHR, 2010). Estudo sobre as experiências de compostagem de RSU na cidade de São Paulo, realizado por Siqueira e Assad (2015), apresenta um histórico que mostra que as unidades centralizadas têm risco de falir, aproximadamente, três vezes maior do que as unidades descentralizadas.

\section{Unidade de digestão anaeróbica: biodigestor (tratamento biológico)}

A digestão anaeróbica é realizada por microrganismos na ausência de oxigênio e gera e captura o gás metano (biogás) para posteriormente utilizá-lo como fonte de energia. Os biodigestores seguem a ordem de prioridade da PNRS (BRASIL, 2010), porque evitam a disposição final de resíduos com possibilidade de tratamento.
Em relação aos custos de investimento e operação e manutenção, a FADE (2014) cita que as unidades com capacidade de processamento de $66 \mathrm{t} /$ dia possuem custos unitários de investimento de R \$37,12/t e de operação e manutenção de $\mathrm{R} \$ 100 / \mathrm{t}$. Já as unidades com capacidade de $225 \mathrm{t} /$ dia geram custos de investimento de $\mathrm{R} \$ 35,54 / \mathrm{t}$ e de operação e manutenção de $\mathrm{R}$ \$50/t. A receita dessas unidades pode ser obtida com a venda da energia do biogás e do composto orgânico resultante. A quantidade de energia gerada pelos biodigestores pode ser estimada por modelos matemáticos e pela definição de alguns parâmetros técnicos da tecnologia (SILVA, 2015).

Entre as principais características dos digestores anaeróbicos, estão a redução da emissão de GEE dos RSU e a capacidade de reduzir o volume do resíduo orgânico em 70\% (HARTMANN; AHRING, 2005). Em usinas que também realizam a compostagem, a diminuição da quantidade de resíduos dispostos em aterro é igual a $100 \%$ do resíduo orgânico tratado. Apesar da redução da emissão de GEE, os digestores anaeróbicos ainda os geram. Dados da European Commission (2006) apontam que são emitidos entre 0 e 411 gramas de gás metano e entre 181 e $520 \mathrm{~kg}$ de gás carbônico para cada tonelada de resíduo tratado.

Os biodigestores anaeróbicos geram, aproximadamente, o mesmo número de empregos que as unidades de compostagem. Entretanto, em biodigestores anaeróbicos que também realizam a compostagem, a quantidade de empregos gerada pode até dobrar (KALYANI; PANDEY, 2014).

Em relação à viabilidade, os biodigestores possuem menor viabilidade em relação às unidades de compostagem, por um pequeno aumento na exigência de especialização da mão de obra. Kalyani e Pandey (2014) afirmam que usinas de larga escala (de modelo centralizado) na Índia tiveram insucesso diante da dificuldade de obter resíduos orgânicos separados para abastecer o processo, diferentemente das usinas de menor escala (de modelo descentralizado), que vêm obtendo bons resultados.

\section{Unidade de incineração: tratamento térmico}

$\mathrm{O}$ tratamento térmico de RS realiza a queima controlada e devidamente preparada dos resíduos para diminuir o seu volume e gerar energia. Entre as tecnologias térmicas, a incineração é a mais antiga e utilizada. Dependendo do tipo de material, o processo pode ou não seguir o âmbito regulatório. Para estar de acordo com a ordem de prioridade da PNRS (BRASIL, 2010), deve-se evitar a incineração de materiais recicláveis, já que a reciclagem é prioridade em relação ao tratamento de resíduos.

As unidades de incineração com capacidade máxima de $650 \mathrm{t} /$ dia possuem custos unitários de investimento de R $\$ 95,31 / t$ e de operação e manutenção de $\mathrm{R} \$ 108,88 / \mathrm{t}$. Já as unidades com capacidade de 1,300 t/dia geram custos de investimento de $\mathrm{R}$ \$75,74/t e de operação e manutenção de R \$ 95,46/t (FADE, 2014). Essas unidades podem gerar receita com a venda da energia elétrica gerada pela queima.

Entre os tratamentos mencionados, o térmico possui o maior índice de redução de volume dos resíduos, podendo variar entre 80 e 90\% (LOMBARDI; CARNEVALE; CORTI, 2015). Em relação às emissões de GEE, $\mathrm{o} \mathrm{CO}_{2}$ é o principal GEE emitido pelos incineradores de RSU, sendo gerados, em média, $0,415 \mathrm{mg}$ de $\mathrm{CO}_{2}$ danoso ao meio ambiente a cada $1 \mathrm{mg}$ de resíduo processado. Já o $\mathrm{CH}_{4}$ não é gerado durante as operações normais da incineração (JOHNKE, 2002).

O ILSR (1997) afirma que as unidades de incineração geram aproximadamente um emprego para cada 10 mil toneladas anuais de RSU tratadas. Outro ponto negativo dessas unidades de tratamento é o alto risco de insucesso de 
incineradores em países de média e baixa renda (por exemplo, a Índia). Essas regiões não possuem domínio da tecnologia, há escassez de mão de obra qualificada e o poder calorífico dos RS é baixo, o que prejudica o rendimento de geração de energia (YAP; NIXON, 2015). Segundo Themelis et al. (2013), deve-se investir em usinas de tratamento térmico com processamento de, pelo menos, 200 mil toneladas por ano, uma vez que quantidades menores tornam o investimento financeiramente inviável.

\section{METODOLOGIA}

A presente pesquisa utilizou o MMAD AHP, método que mais se destaca na gestão de RSU. Soltani et al. (2015) citam um estudo que aponta o método AHP como o mais usado (65\%) nos artigos científicos publicados sobre tomada de decisão na área de gestão de RSU. Segundo Yap e Nixon (2015), o AHP decompõe um problema complexo em níveis hierárquicos, permitindo avaliar e apontar a melhor alternativa para o alcance de um objetivo geral, por meio de diferentes critérios, com importância ponderada. A aplicação desta pesquisa seguiu as etapas apontadas por Saaty (1980) (ver Quadro 1).

A Figura 1 mostra a estrutura hierárquica da AHP desta pesquisa, juntamente com os pesos dos critérios e subcritérios calculados com base na avaliação de especialistas. A estrutura hierárquica destaca o objetivo da AHP, os critérios e subcritérios de avaliação e as alternativas de mudança avaliadas. Para alcançar o objetivo geral, analisou-se a influência que cada uma das alternativas tem sobre os critérios/subcritérios escolhidos.

Na etapa 4, a quantidade de RSU gerada no município é um dado de entrada essencial para projetar resultados dos subcritérios de cada alternativa avaliada. Este trabalho considerou a média anual de geração de RSU calculada com base nos valores projetados para um período de 20 anos (2016 a 2035). Primeiramente, projetou-se a quantidade de RSU gerada no município no ano de 2015. Na pesquisa de campo, foi constatado que não existe estudo primário que estime a quantidade de RSU gerados pelo município, e por esse motivo se utilizou a taxa de geração por unidade ( $\mathrm{kg} / \mathrm{dia} / \mathrm{hab})$ sugerida por Christensen (2011). Partindo da premissa de que a taxa de geração da região é igual à taxa média do Nordeste, de 0,982 kg/dia/hab. (ABRELPE, 2015), os 266,022 habitantes de Juazeiro do Norte (IBGE, 2015) geram o total de 261 toneladas de RSU por dia, ou seja, 95,350 toneladas por ano. O valor de 95,350 t/ano serviu de base para projetar a geração de RSU para os próximos 20 anos. O cálculo desses valores considerou a taxa média de crescimento anual de geração de RSU no Ceará. O valor médio de 2,69\% foi calculado utilizando as taxas dos anos de 2010 a 2014 apontadas pela Associação Brasileira de Empresas de Limpeza Pública e Resíduos Especiais - ABRELPE (2012; 2013; 2014; 2015). No fim, estima-se que a geração de RSU de Juazeiro do Norte entre 2016 e 2035 cresça de 95,350 para 162,172 toneladas por ano, ou seja, que aumente $70 \%$ nos próximos 20 anos. A média anual calculada é de 44,623 toneladas de material reciclável, 72,672 toneladas de material orgânico e 10,200 toneladas de outros materiais, levando em consideração a composição gravimétrica apontada por SEMASP (2013).

Além da quantidade de RSU gerada, características de diferentes unidades de tratamento de RS levantadas na literatura foram usadas na avaliação das alternativas (ver Anexo).

Por meio desses dados/informações e de modelos matemáticos (Quadro 2), foram estimados os valores dos subcritérios. Especificamente para os critérios técnico e regulatório, utilizou-se avaliação qualitativa. Ao término do cálculo de cada subcritério, os valores quantitativos e qualitativos foram comparados entre as alternativas e, depois, ponderados em uma escala de 0 a $100 \%$. A seguir, descreve-se como foi realizada a avaliação de cada um dos subcritérios.

\section{Avaliação econômica}

A avaliação das alternativas no subcritério de "custos de implantação, operação e manutenção" considerou o valor (R\$/t) apontado por FADE (2014), sendo esse

Quadro 1 - Etapas do método analytic hierarchy process.

\begin{tabular}{|c|c|}
\hline Etapas & Observações \\
\hline 1-Definição do objetivo geral & $\begin{array}{c}\text { Haja vista a inexistência de unidades de tratamento de RSU em Juazeiro do Norte, o objetivo geral da AHP é: "Definir a alternativa de } \\
\text { tratamento de RSU mais sustentável, que esteja em consonância com o âmbito regulatório (Lei Federal 12,305 - PNRS)". }\end{array}$ \\
\hline 2-Definição das alternativas & $\begin{array}{l}\text { Foram definidas cinco alternativas de tratamento de RSU baseadas em boas práticas presentes no Brasil e no Mundo, divididas } \\
\text { em modelos centralizados e descentralizados. As alternativas definidas mesclam unidades de triagem (manual ou automatizada), } \\
\text { unidades de compostagem (centralizada ou descentralizada), biodigestores (centralizado ou descentralizado) e incinerador. }\end{array}$ \\
\hline $\begin{array}{l}\text { 3-Definição dos critérios/subcritérios } \\
\text { relevantes para alcançar o objetivo }\end{array}$ & $\begin{array}{l}\text { Em relação aos critérios/subcritérios, foram definidos cinco critérios e sete subcritérios, com base em Chang e Pires (2015), que se } \\
\text { julgou serem eficientes para avaliar as alternativas e passíveis de coleta e mensuração. }\end{array}$ \\
\hline $\begin{array}{l}\text { 4-Avaliação das alternativas em } \\
\text { relação aos critérios }\end{array}$ & $\begin{array}{l}\text { Nesta etapa, foram utilizadas diversas técnicas quantitativas de projeção, com o auxílio de dados/informações coletados em campo e } \\
\text { em fontes secundárias (ex.: Ministério das Cidades, Banco Mundial, CEMPRE, IPEA, WWF e FADE). }\end{array}$ \\
\hline $\begin{array}{l}\text { 5-Avaliação da importância relativa } \\
\text { de cada critério }\end{array}$ & $\begin{array}{l}\text { Como sugerido por Chang e Pires (2015), esta pesquisa aplicou questionários a especialistas da área, sendo um da Universidade } \\
\text { Federal do Ceará (UFC), um da HQ Engenharia - Consultoria Ambiental, um da Secretaria das Cidades do Ceará, um da Ecoletas } \\
\text { Ambiental, um do Instituto Consciência, um da ALS Bioenergy Corp., um da Secretaria Estadual do Meio Ambiente CE (SEMA) e um } \\
\text { da Secretaria da Ciência, Tecnologia e Educação Superior do Ceará (SECITECE). Os oito especialistas compararam todos os critérios } \\
\text { par a par, com o apoio da escala fundamental de Saaty (1980). Já para os subcritérios, seguiram o mesmo procedimento com os } \\
\text { subcritérios econômico e ambiental. Obs.: Nos critérios social, técnico e regulatório, os pesos dos subcritérios foram de } 1 \text { (100\%) em } \\
\text { relação aos respectivos critérios, já que se considerou somente um subcritério em cada. }\end{array}$ \\
\hline $\begin{array}{l}\text { 6-Determinação da avaliação global } \\
\text { de cada alternativa }\end{array}$ & $\begin{array}{l}\text { Nesta etapa, este trabalho utilizou o software SuperDecisions }{ }^{\oplus} \text {. Os pesos definidos nas etapas anteriores foram inseridos no software, } \\
\text { o qual avalia todas as alternativas e aponta o ranking das alternativas em relação a cada subcritério e o ranking geral das alternativas. } \\
\text { No fim, realizou-se uma análise de sensibilidade com o próprio software, para ampliar a interpretação e melhor orientar a escolha da } \\
\text { alternativa. }\end{array}$ \\
\hline
\end{tabular}

RSU: resíduos sólidos urbanos; AHP: analytic hierarchy process; CEMPRE: Compromisso Empresarial para Reciclagem; IPEA: Instituto de Pesquisa Econômica Aplicada; WWF: World Wide Fund for Nature; FADE: Fundação de Apoio ao Desenvolvimento da Universidade Federal de Pernambuco.

Fonte: elaborada pelos autores (2019). 
valor multiplicado pela quantidade anual de RSU processada em cada unidade. No caso da avaliação com o subcritério "receita gerada por produtos", foi considerado para os materiais recicláveis (alternativas 1, 2, 3, 4 e 5) o valor médio de venda igual a $R \$ 0,63 / \mathrm{kg}$, calculado com base nos valores de venda coletados em pesquisa de campo. Já a receita da venda do composto (alternativas 1 , 2,3 e 4) foi calculada ao multiplicar-se o preço médio por tonelada, de $\mathrm{R} \$ 125 / \mathrm{t}$ (CEMPRE, 2016), pela quantidade anual de resíduo orgânico tratado e pelo percentual médio de geração de composto, de 35\% (WWF BRASIL, 2015). O cálculo da receita da venda da energia gerada utilizou a tarifa do Nordeste de R\$ 292,22/MWh (BRASIL, 2015) e as Equações 1 e 2, para a alternativa 5, e 3 e 4 , para as alternativas 3 e 4 .

Segundo Silva (2015), a quantidade da energia elétrica produzida por usinas de incineração de RSU pode ser calculada usando as seguintes Equações 1 e 2:

$P_{i n c}=\eta_{v} \times \eta_{g} \times M i(t) \times P C I$

Ener. $=P_{i n c} \times$ Horas ano $\times \mathrm{FC}$

Em que:

Potência elétrica $P_{i n c}[\mathrm{Mw}]=$ calculada com base nos valores da eficiência do ciclo a vapor $\left(\eta_{v}\right)$, da eficiência do gerador elétrico $\left(\eta_{g}\right)$, da taxa de incineração de RSU $(M i(t))$, em kg/s, e do poder calorífico inferior do RSU da entrada da caldeira $(P C I)$, em MJ/kg;

Energia elétrica $=$ estimada ao multiplicar-se a potência elétrica $\left(P_{i n c}\right)$ pela quantidade de horas operadas no ano, levando em consideração o percentual de tempo, em um ano, em que o equipamento está produzindo eletricidade em capacidade plena (FC). O cálculo da quantidade de energia gerada pelo incinerador (alternativa 5) considerou $\eta_{v}=33 \%$ (USEPA, 2005), $\eta_{g}=98 \%$ (HENRIQUES, 2004), $M i(t)$ igual a $2,94 \mathrm{~kg} / \mathrm{s}$ (material orgânico e outros), $P C I$ $=2,98 \mathrm{MJ} / \mathrm{kg}(\mathrm{FEAM}, 2012)$ e $\mathrm{FC}=90 \%$.

Em relação à quantidade de energia produzida nos biodigestores, Silva (2015) afirma que a energia elétrica, gerada pela queima do gás metano produzido em biodigestores anaeróbicos, pode ser estimada por meio das Equações 3 e 4 .

$P_{\text {digest. }}=\eta_{\mathrm{m}} \times \eta_{g} \times P C I_{\mathrm{CH} 4} \times \mathrm{R}_{\mathrm{B}}(t)$

Ener. $=P_{\text {disgest. }} \times$ Horas ano $\times \mathrm{FC}$

A Equação 3 calcula a potência gerada pelo $\mathrm{CH}_{4}$ produzido em biodigestores anaeróbicos $\left(P_{\text {digest. }}\right)$ e, para isso, são utilizados os parâmetros de eficiência térmica dos motores de combustão interna $\left(\eta_{\mathrm{m}}\right)$, eficiência do gerador elétrico $\left(\eta_{g}\right)$, poder calorífico inferior do gás metano $\left(P C I_{\mathrm{CH} 4}\right)$, em $\mathrm{MJ} / \mathrm{m}^{3}$, e taxa de produção de metano $\left(\mathrm{R}_{\mathrm{B}}(t)\right)$, em m³ $/ \mathrm{s}$. Já a Equação 4 estima a energia elétrica ao multiplicar a potência elétrica $\left(P_{\text {digest. }}\right)$ pela quantidade de horas operadas no ano, levando em consideração o percentual de tempo, em um ano, em que o equipamento está produzindo eletricidade em capacidade plena (FC). Neste trabalho, a quantidade de energia produzida nos biodigestores (alternativas 3 e 4) foi calculada com base nos valores de $\eta_{\mathrm{m}}=0,28$ (ICLEI, 2010), $\eta_{g}=98 \%$ (HENRIQUES, 2004), $P C I_{\mathrm{CH} 4}=36$ (SILVA, 2010). Para o $\mathrm{R}_{\mathrm{B}}(t)$, assumiu-se o valor médio de Moletta, Verrier e Albagnac (1986), de $74 \mathrm{~m}^{3} / \mathrm{t}$ de material orgânico (igual a $0,19 \mathrm{~m}^{3} / \mathrm{s}$ no cenário em estudo), e o valor da FC foi tomado como $90 \%$.

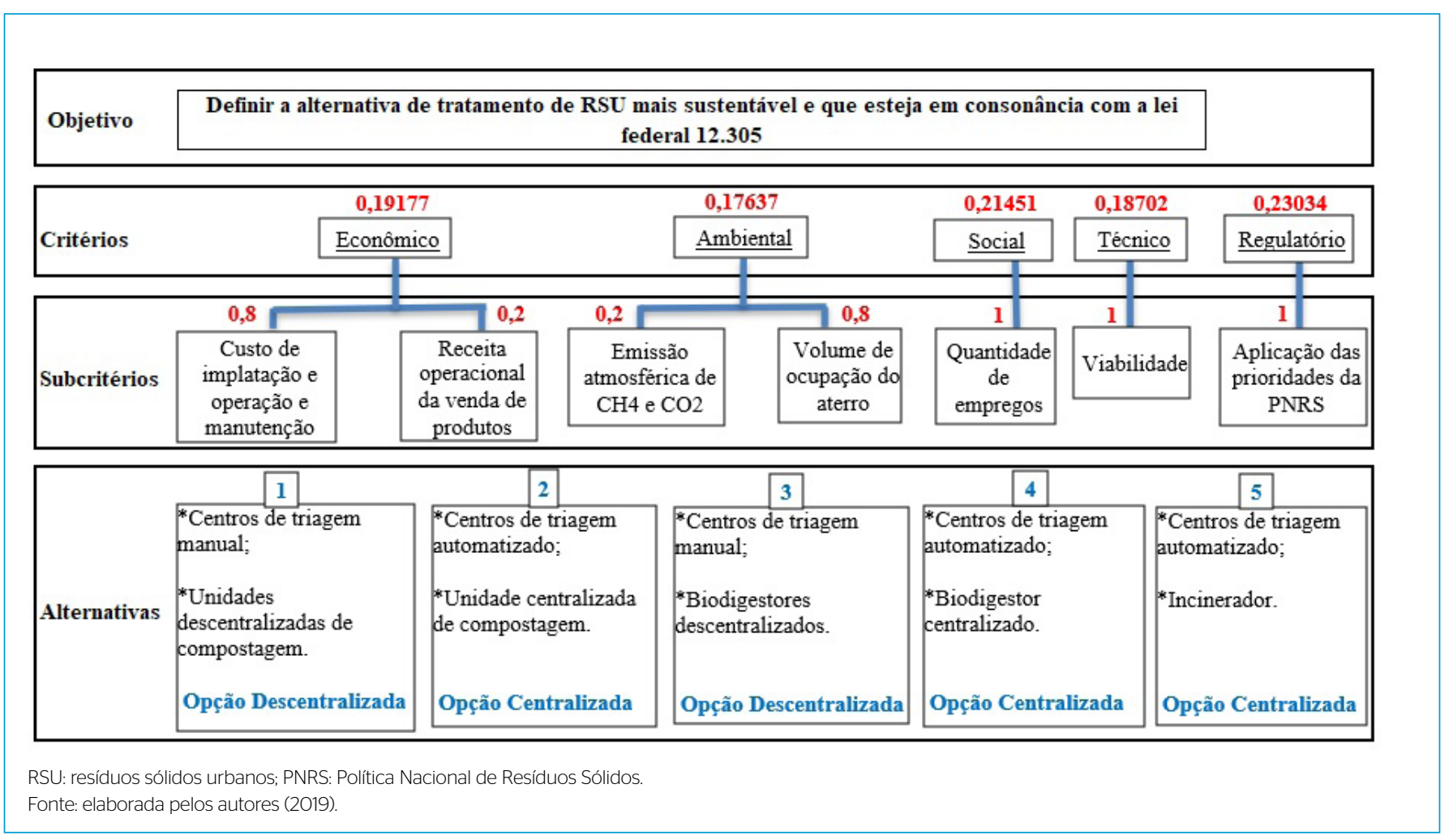

Figura 1 - Estrutura hierárquica do método analytic hierarchy process. 


\section{Avaliação ambiental}

A avaliação quanto ao subcritério "emissão atmosférica de $\mathrm{CH}_{4}$ e $\mathrm{CO}_{2}$ " considerou as taxas de emissões por quantidade de resíduo tratado citadas por FADE (2014), Inácio, Bettio e Miller (2010), European Commission (2006) e Johnke (2002). Além disso, utilizou-se a ferramenta LandGEM para estimar a quantidade $\mathrm{CH}_{4}$ e $\mathrm{CO}_{2}$ produzida pelos RSU dispostos em aterros.

A ferramenta LandGEM, criada pela Agência de Proteção Ambiental dos Estados Unidos (USEPA), é comumente usada em estudos de previsão de produção de gases por meio de RSU (CHO; MOON; KIM, 2012; KARANJEKAR et al., 2015). Para seu cálculo, é necessário inserir na planilha do programa os valores de $i, n, \mathrm{~K}, \mathrm{~L}_{\mathrm{o}}, \mathrm{NMOC}$, volume de metano e $\mathrm{M}_{i}$, em que: $i$ é o ano de início e $n$ o ano de término do funcionamento do aterro; $\mathrm{K}$ é a taxa de geração de metano; $\mathrm{L}_{\mathrm{o}}$ é a capacidade potencial de geração de metano; NMOC é a concentração de compostos orgânicos voláteis não metânicos (em ppmv hexano); o volume de metano é dado em \%; e $\mathrm{M}_{i}$ é a quantidade de RSU que entra no aterro ou lixão todo ano.
Esta pesquisa adotou os critérios da USEPA (2005), que define os valores padrão de $\mathrm{k}=0,05\left(\right.$ ano $\left.^{-1}\right) ; \mathrm{L}_{0}=170\left(\mathrm{~m}^{3} / \mathrm{mg}\right)$; concentração de $\mathrm{NMOC}=600(\mathrm{ppmv}$ hexano) considerando a inexistência de resíduos perigosos e volume de metano $=50 \%$. No fim, no cálculo do grau de importância, ponderou-se a influência do $\mathrm{CH}_{4}$ e do $\mathrm{CO}_{2}$ para o efeito estufa (o $\mathrm{CH}_{4}$ é 21 vezes mais nocivo do que o $\mathrm{CO}_{2}$ ) utilizando-se o disposto por Nobre, Reid e Veiga (2012).

O subcritério "volume de ocupação do aterro" considera a redução da área de ocupação do aterro em consequência da redução do volume dos resíduos tratados. Segundo Younes et al. (2016), o espaço ocupado pelos RSU dispostos em aterro/lixões pode ser estimado por meio da Equação 5.

Área $=\mathrm{R} \times \mathrm{L} \times$ Pop $\times 1,5 /(\rho$ bulk $\times \mathrm{H})$

Em que:

$\mathrm{R}$ = taxa de geração per capita por ano de RSU (kg/hab./ano);

Quadro 2 - Características de cada tipo de unidade de tratamento de resíduos sólidos urbanos.

\begin{tabular}{|c|c|c|c|c|c|c|c|c|}
\hline \multirow{2}{*}{\multicolumn{2}{|c|}{$\begin{array}{l}\text { Capacidade } \\
\text { de processamento }\end{array}$}} & \multicolumn{2}{|c|}{ Centro de triagem } & \multicolumn{2}{|c|}{ Unidade de compostagem } & \multicolumn{2}{|c|}{ Biodigestor (com compostagem) } & \multirow{3}{*}{$\begin{array}{c}\text { Incinerador } \\
\text { Centralizado } \\
650 \text { tonela- } \\
\text { das de RSU/ } \\
\text { dia }\end{array}$} \\
\hline & & \multirow{2}{*}{$\begin{array}{l}\text { Manual } \\
10-30 \text { mil } \\
\text { habitantes }\end{array}$} & \multirow{2}{*}{$\begin{array}{c}\text { Automatizado } \\
250 \text { mil -1mi- } \\
\text { Ihão habitantes }\end{array}$} & \multirow{2}{*}{$\begin{array}{c}\text { Descentralizada } \\
\begin{array}{c}\text { 10 - } 30 \text { mil habi- } \\
\text { tantes }\end{array}\end{array}$} & \multirow{2}{*}{$\begin{array}{l}\text { Centralizada } \\
250 \text { mil - } 1 \text { mi- } \\
\text { Ihão habitantes }\end{array}$} & \multirow{2}{*}{\begin{tabular}{c|} 
Descentralizado \\
$\begin{array}{c}66 \text { toneladas de } \\
\text { RSU/dia }\end{array}$
\end{tabular}} & \multirow{2}{*}{\begin{tabular}{|c|} 
Centralizado \\
225 toneladas de \\
RSU/dia
\end{tabular}} & \\
\hline Critério & Subcritério & & & & & & & \\
\hline \multirow[t]{2}{*}{ Econômico } & $\begin{array}{l}\text { Custos de } \\
\text { implantação } \\
\text { e operação e } \\
\text { manutenção } \\
(\mathrm{R} \$ / \mathrm{t})\end{array}$ & 502,5 & 179,5 & 86 & 84,3 & 137,12 & 85,54 & 204,19 \\
\hline & $\begin{array}{l}\text { Receita } \\
\text { operacional } \\
\text { da venda de } \\
\text { produtos }(R \$)\end{array}$ & $\begin{array}{l}\text { Venda do } \\
\text { material } \\
\text { reciclável }\end{array}$ & $\begin{array}{l}\text { Venda do } \\
\text { material } \\
\text { reciclável }\end{array}$ & $\begin{array}{l}\text { Venda do } \\
\text { composto }\end{array}$ & $\begin{array}{l}\text { Venda do } \\
\text { composto }\end{array}$ & $\begin{array}{c}\text { Venda da energia } \\
\text { elétrica + venda do } \\
\text { composto }\end{array}$ & $\begin{array}{l}\text { Venda da energia } \\
\text { elétrica + venda do } \\
\text { composto }\end{array}$ & $\begin{array}{l}\text { Venda da } \\
\text { energia } \\
\text { elétrica }\end{array}$ \\
\hline \multirow{3}{*}{ Ambiental } & \multirow[t]{2}{*}{$\begin{array}{l}\text { Emissão } \\
\text { atmosférica de } \\
\mathrm{CH}_{4} \mathrm{eCO}_{2}(\mathrm{t})\end{array}$} & Não emite $\mathrm{CH}_{4}$ & Não emite $\mathrm{CH}_{4}$ & $\begin{array}{c}\text { Entre } \mathrm{O}, 004 \text { e } \mathrm{O}, 010 \\
\text { toneladas de } \mathrm{CH}_{4} \\
\text { para cada tonelada } \\
\text { de resíduo tratado, } \\
\text { na base úmida } \\
\text { e na base seca, } \\
\text { respectivamente }\end{array}$ & $\begin{array}{c}\text { Entre } 0,004 \text { e } \\
\text { o,010 toneladas } \\
\text { de } \mathrm{CH}_{4} \text { para cada } \\
\text { tonelada de } \\
\text { resíduo tratado, } \\
\text { na base úmida } \\
\text { e na base seca } \\
\text { respectivamente }\end{array}$ & $\begin{array}{c}\text { Entre } \mathrm{O} \text { e } 411 e-6 \\
\text { toneladas de } \mathrm{CH}_{4} \\
\text { para cada tonelada } \\
\text { de resíduo } \\
\text { orgânico tratado }\end{array}$ & $\begin{array}{c}\text { Entre } \mathrm{O} \text { e } 411 e-6 \\
\text { toneladas de } \mathrm{CH}_{4} \\
\text { para cada tonelada } \\
\text { de resíduo orgânico } \\
\text { tratado }\end{array}$ & Não emite $\mathrm{CH}_{4}$ \\
\hline & & Não emite $\mathrm{CO}_{2}$ & Não emite $\mathrm{CO}_{2}$ & Não emite $\mathrm{CO}_{2}$ & Não emite $\mathrm{CO}_{2}$ & $\begin{array}{c}\text { Entre } 0,181 \text { e } 0,52 \mathrm{O} \\
\text { toneladas de } \mathrm{CO}_{2} \\
\text { para cada tonelada } \\
\text { de resíduo } \\
\text { orgânico tratado }\end{array}$ & $\begin{array}{l}\text { Entre } 0,181 \text { e } 0,520 \\
\text { toneladas de } \mathrm{CO}_{2} \\
\text { para cada tonelada } \\
\text { de resíduo orgânico } \\
\text { tratado }\end{array}$ & $\begin{array}{c}\mathrm{O}, 415 \\
\text { toneladas de } \\
\mathrm{CO}_{2} \text { para cada } \\
\text { tonelada de } \\
\text { RSU tratada }\end{array}$ \\
\hline & $\begin{array}{l}\text { Volume de } \\
\text { ocupação do } \\
\text { aterro }\left(\mathrm{m}^{2}\right)\end{array}$ & $\begin{array}{l}\text { Reduz 100\% } \\
\text { do resíduo } \\
\text { triado e } \\
\text { reciclado }\end{array}$ & $\begin{array}{l}\text { Reduz } 100 \% \text { do } \\
\text { resíduo triado e } \\
\text { reciclado }\end{array}$ & $\begin{array}{l}\text { Reduz 100\% do } \\
\text { resíduo orgânico } \\
\text { tratado }\end{array}$ & $\begin{array}{l}\text { Reduz 100\% do } \\
\text { resíduo orgânico } \\
\text { tratado }\end{array}$ & $\begin{array}{l}\text { Reduz } 100 \% \text { do } \\
\text { resíduo orgânico } \\
\text { tratado }\end{array}$ & $\begin{array}{l}\text { Reduz } 100 \% \text { do } \\
\text { resíduo orgânico } \\
\text { tratado }\end{array}$ & $\begin{array}{l}\text { Reduz entre } \\
80 \text { e } 90 \% \\
\text { do resíduo } \\
\text { tratado }\end{array}$ \\
\hline \multicolumn{2}{|l|}{$\begin{array}{l}\text { Social. } \\
\text { Empregos }\end{array}$} & $\begin{array}{c}50 \text { empregos } \\
\text { para cada } 10 \\
\text { mil toneladas } \\
\text { anuais de RSU } \\
\text { tratadas }\end{array}$ & $\begin{array}{l}10 \text { empregos } \\
\text { para cada } 10 \text { mil } \\
\text { toneladas anuais } \\
\text { de RSU tratadas }\end{array}$ & $\begin{array}{l}14 \text { empregos } \\
\text { para cada } 10 \text { mil } \\
\text { toneladas anuais } \\
\text { de RSU tratadas }\end{array}$ & $\begin{array}{l}4 \text { empregos } \\
\text { para cada } 10 \text { mil } \\
\text { toneladas anuais } \\
\text { de RSU tratadas }\end{array}$ & $\begin{array}{l}28 \text { empregos } \\
\text { para cada } 10 \text { mil } \\
\text { toneladas anuais } \\
\text { de RSU tratadas }\end{array}$ & $\begin{array}{c}8 \text { empregos para } \\
\text { cada } 10 \text { mil toneladas } \\
\text { anuais de RSU } \\
\text { tratadas }\end{array}$ & $\begin{array}{c}1 \text { emprego } \\
\text { para cada } 10 \\
\text { mil toneladas } \\
\text { anuais de RSU } \\
\text { tratadas }\end{array}$ \\
\hline \multicolumn{2}{|l|}{$\begin{array}{l}\text { Técnico. } \\
\text { Viabilidade }\end{array}$} & Alta & Média & Alta & Baixa & Média & Baixa & Muito baixa \\
\hline \multicolumn{2}{|c|}{$\begin{array}{l}\text { Regulatório. } \\
\text { Aplicação das prioridades da } \\
\text { PNRS }\end{array}$} & Alta & Alta & Alta & Alta & Alta & Alta & Alta \\
\hline
\end{tabular}

RSU: resíduos sólidos urbanos; PNRS: Política Nacional de Resíduos Sólidos.

Fonte: elaborada pelos autores (2019). 
$\mathrm{L}=\mathrm{o}$ tempo de utilização do aterro/lixão (anos);

Pop = quantidade total de pessoas, $\rho$ bulk é a densidade dos resíduos $\left(\mathrm{kg} / \mathrm{m}^{3}\right)$; $\mathrm{H}=$ é a altura das montanhas de resíduos no aterro (m).

Os valores dos parâmetros $\mathrm{L}, \rho b u l k$ e $\mathrm{H}$ foram definidos com base nas recomendações do estudo de Younes et al. (2016). De acordo com esses autores, o valor de $800 \mathrm{~kg} / \mathrm{m}^{3}$ é comumente usado como densidade média dos resíduos ( $\rho b u l k)$ em diversos estudos na área; o valor da altura das montanhas de resíduos $(\mathrm{H})$ deve variar de 15 a 30 metros (usou-se o valor médio de $22,5 \mathrm{~m}$ ); e o tempo médio mais comum de utilização de um aterro/lixão é de 20 anos (L).

Após a aplicação da Equação 5, o resultado foi multiplicado pelos valores de redução dos resíduos apontados por Chester, Martin e Sathaye (2008), WWF Brasil (2015) e Lombardi, Carnevale e Corti (2015).

\section{Avaliação social, técnica e regulatória}

A avaliação das alternativas no subcritério social "emprego" considerou as taxas de geração de emprego nas unidades de tratamento citadas por Brasil (2008) e ILSR (1997). A avaliação das alternativas no critério técnico de viabilidade analisou as informações técnicas e os históricos levantados na literatura; a viabilidade de cada unidade de tratamento foi classificada como alta, média, baixa ou muito baixa, recebendo a pontuação 10, 6, 2 e 0, respectivamente. Por fim, a avaliação das alternativas no critério regulatório levou em consideração as prioridades apresentadas na PNRS; cada uma das unidades de tratamento foi classificada em alta, média, baixa ou muito baixa, recebendo a pontuação $10,6,2$ e 0 , respectivamente.

\section{RESULTADOS E DISCUSSÃO}

Os resultados apresentados levaram em consideração um conjunto de premissas de cenários ideais. Nas alternativas 1 e 2, parte-se do pressuposto que $100 \%$ dos materiais recicláveis são separados e vendidos nos centros de triagem, $100 \%$ da matéria orgânica é tratada nas unidades de compostagem, sendo vendido todo o fertilizante produzido, e o restante dos materiais (outros resíduos) é destinado ao aterro. Nas alternativas 3 e 4, 100\% dos materiais recicláveis são separados e vendidos nos centros de triagem, $100 \%$ da matéria orgânica é tratada nos biodigestores, sendo todo o fertilizante e a energia gerada vendidos, e o restante dos materiais é destinado ao aterro. Já na alternativa 5, 100\% dos materiais recicláveis são separados e vendidos nos centros de triagem, e 100\% da matéria orgânica e de outros materiais são queimados no incinerador, sendo toda a energia gerada vendida. A Figura 2 mostra o ranking das alternativas em cada um dos sete diferentes subcritérios de avaliação.

A alternativa 1 lidera o ranking nos subcritérios "emissão de GEE", "viabilidade" e "harmonização com a PNRS" e destaca-se na geração de empregos (segundo lugar), entretanto não obtém bons resultados econômicos (custos e receita). A alternativa 2 lidera em "emissão de GEE", "harmonização com a PNRS" e "custos"; por outro lado, possui a segunda pior colocação em "empregos" e "viabilidade".

A alternativa 3 obtém ótimos resultados em "harmonização com a PNRS" (primeiro lugar), "empregos" (primeiro lugar), "receita" (primeiro lugar) e "viabilidade" (segundo lugar) e resultado ruim em "emissão de GEE” (segundo pior). A alternativa 4 destaca-se na primeira posição em "receita" e "viabilidade", e na segunda posição em "custos" (diferença de somente $0,18 \%$ para a primeira

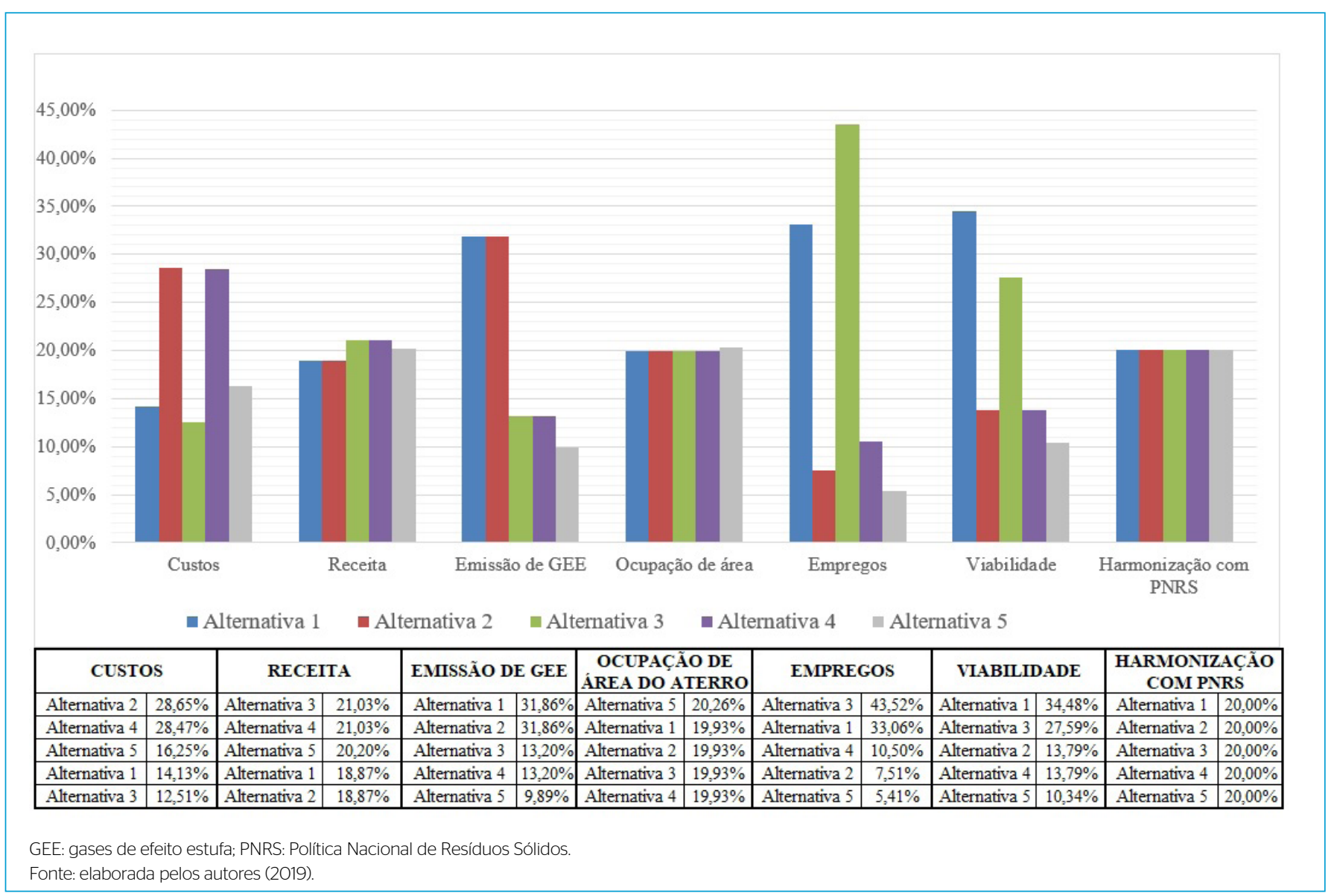

Figura 2 - Ranking das alternativas por critério. 
colocada), no entanto apresenta deficiência em "emissão de GEE" (segunda pior) e "empregos" (terceira pior).

Por fim, a alternativa 5 obtém vantagem em "ocupação de área do aterro" $(0,33 \%$ a mais do que as outras alternativas) e "receita" (somente $0,83 \%$ a menos do que a primeira colocada). Apesar disso, seus resultados são ruins em "viabilidade" (último lugar), "empregos" (último lugar), "emissão de GEE” (último lugar) e "custos" (terceiro pior).

Com os valores apontados no Gráfico 2 e os pesos definidos pelos especialistas, obteve-se o ranking geral das alternativas no método AHP, como pode ser observado na Figura 3.

As alternativas 3 (centro de triagem e digestor anaeróbico descentralizados) e 1 (centro de triagem e unidade de compostagem descentralizados) são apontadas como as opções de tratamento de RSU mais favoráveis para Juazeiro do Norte, com percentual de $25,11 \%$ e $24,97 \%$, respectivamente. As alternativas descentralizadas 3 e 1 levam vantagem sobre as alternativas centralizadas 4, 2 e 5 em virtude, principalmente, da maior geração de empregos e da viabilidade técnica, que se mostra bem maior em experiências no Brasil e na Índia.

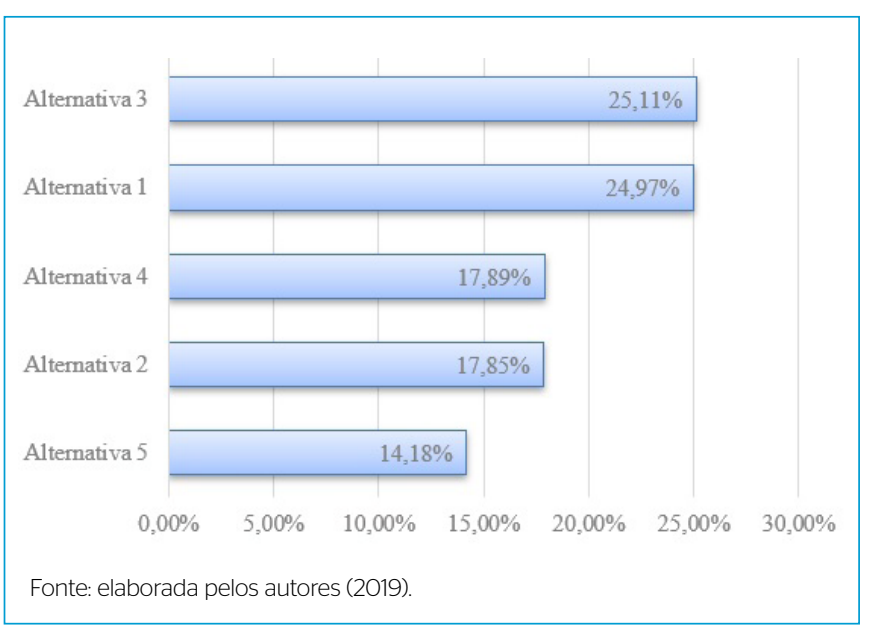

Figura 3 - Ranking geral das alternativas.
As alternativas 4 e 2 aparecem, respectivamente, na terceira e na quarta colocação. Apesar de apresentarem os menores custos, a baixa geração de emprego afeta negativamente seus resultados de forma decisiva, já que o critério social é avaliado como o segundo mais relevante na tomada de decisão. A alternativa 5 (centro de triagem automatizado e incinerador) é a opção de tratamento menos favorável para a região, obtendo resultado $(14,18 \%)$, quase duas vezes menor do que o do primeiro colocado. Entre os sete critérios/subcritérios avaliados, essa alternativa ficou na última posição em três, até mesmo no critério com maior peso ("social").

\section{Análise de sensibilidade}

A análise de sensibilidade foi utilizada para entender como o resultado geral se comportaria com diferentes avaliações nos pesos dos critérios. O grau de importância de cada critério foi alterado individualmente de 0 a $100 \%$, mantendo-se o peso dos demais proporcionalmente constantes.

A Figura 4 apresenta a análise de sensibilidade dos critérios econômico (A) e ambiental (B). A análise de sensibilidade do critério econômico (A) mostra que as alternativas descentralizadas ( 1 e 3 ) respondem negativamente ao crescimento do peso econômico, diferentemente das alternativas centralizadas $(2,4 \mathrm{e} 5)$, que aumentam seus resultados com a evolução do peso desse critério. Do peso 0,5 em diante, a influência do critério no resultado acentua-se e, no peso 0,7 , as alternativas $2 \mathrm{e}$ 4 superam a 1 e a 3 e passam a apresentar os melhores resultados entre as opções.

Quanto à análise de sensibilidade do critério ambiental (B), podemos observar que, à medida que a prioridade ambiental aumenta, os resultados das alternativas 1 e 3 diminuem, enquanto os das alternativas 2 e 5 crescem consideravelmente, principalmente do peso 0,5 em diante. Por volta do peso 0,85 , a alternativa 2 ultrapassa a alternativa 3 e torna-se a segunda melhor opção.

A Figura 5 apresenta a análise a sensibilidade dos critérios social (A) e técnico (B). Na análise de sensibilidade do critério social (A), podemos observar que, à medida que a prioridade social aumenta, os resultados das alternativas 1 e 3 evoluem, enquanto os das alternativas centralizadas 2, 4 e 5 decrescem. Aumenta-se o domínio das opções descentralizadas, e as alternativas 1 e 3 obtêm os melhores resultados em quase todos os pesos ( 0,1 a 1$)$.
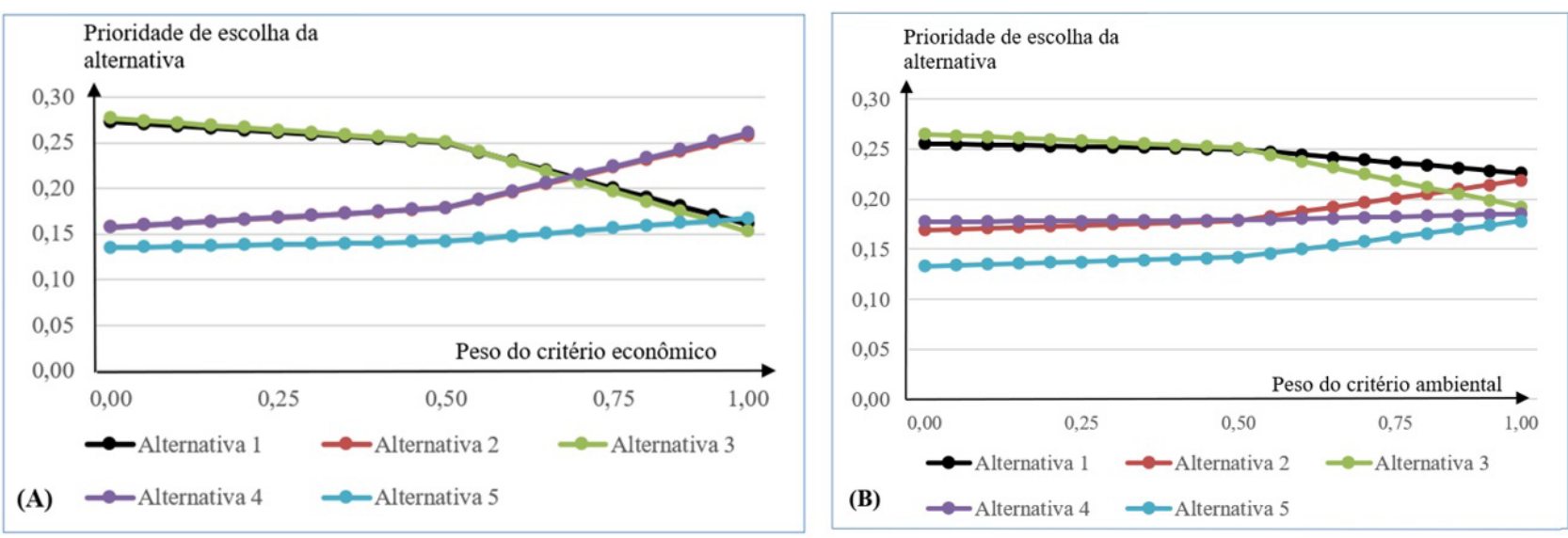

Fonte: elaborada pelos autores (2019).

Figura 4 - Análise de sensibilidade dos critérios econômico e ambiental. 
$\mathrm{Na}$ análise de sensibilidade do critério técnico (B) (Figura 5), as alternativas descentralizadas 1 e 3 obtêm os melhores resultados. Conforme a prioridade técnica aumenta, os resultados das alternativas 1 e 3 melhoram, enquanto os das alternativas centralizadas 2, 4 e 5 pioram. Do peso 0,5 em diante, a alternativa 1 alcança resultados ainda melhores e começa a se distanciar da segunda colocada (alternativa 3).

A Figura 6 trata da análise de sensibilidade do critério regulatório, no qual podemos observar que as alternativas 1 e 3 obtiveram os melhores resultados. À medida que a prioridade regulatória aumenta, os resultados das alternativas 2, 4 e 5 evoluem, enquanto os das alternativas centralizadas 1 e 3 pioram, e os resultados das cinco alternativas tendem a se igualar no peso 1 (100\%).

\section{CONCLUSÕES}

O presente trabalho avaliou e comparou diferentes alternativas de tratamento de RSU para o município de Juazeiro do Norte, no Ceará. Para alcançar esse objetivo, aplicou-se o método de apoio à decisão AHP, com o auxílio de diversas técnicas quantitativas de projeção. No total, foram avaliados cinco diferentes alternativas de tratamento de RSU, modelos centralizado e descentralizado, mesclando três tipos de tratamentos (mecânico, biológico e térmico) e considerando-se os critérios econômico (custo e receita), ambiental (emissão de GEE e volume de ocupação do aterro), social (emprego), técnico (viabilidade) e regulatório (aplicação das prioridades da PNRS).

Com base nos resultados obtidos, as alternativas descentralizadas 1 e 3 apresentam-se como as opções mais favoráveis para a região de Juazeiro do Norte. Nessa situação, os benefícios de maior geração de emprego e viabilidade técnica levam vantagem sobre o impacto negativo de maiores custos. Os resultados também destacam a grande diferença entre os impactos das alternativas com tratamento biológico e das com tratamento térmico. As especificidades da região não favorecem o tratamento térmico - exemplos disso são a dificuldade de formar consórcio entre municípios da região com o intuito de obter resíduos suficientes para a queima e o grande percentual de resíduos orgânicos gerados, que diminui o poder calorífico dos suprimentos das usinas térmicas e causa impacto negativo na geração de energia e na viabilidade econômica da unidade.

A análise de sensibilidade de cada um dos critérios foi empregada para entender como o resultado geral do método AHP se comportaria com diferentes priorizações dos critérios, dependendo dos tomadores de decisões. Na maioria das análises realizadas, os resultados obtidos foram semelhantes (alternativas 1 e 3 nas primeiras colocações e alternativas 2, 4 e 5 nas últimas posições). Entretanto, constatou-se que, em uma avaliação na qual o critério econômico tivesse peso superior ou igual a $70 \%$, o resultado geral mudaria de forma significante e as alternativas decentralizadas 2 e 4 seriam apontadas como as melhores opções de tratamento de RSU.

Destaca-se que o estudo se restringiu a avaliar cinco alternativas de tratamento e sete subcritérios. Sugere-se que outras unidades de tratamento de RSU (por exemplo, unidades de pirólise, gaseificação e arco de plasma) e outros subcritérios de avaliação (como receita gerada pela venda dos créditos de carbono, emissão atmosférica de dióxido de nitrogênio, emissão

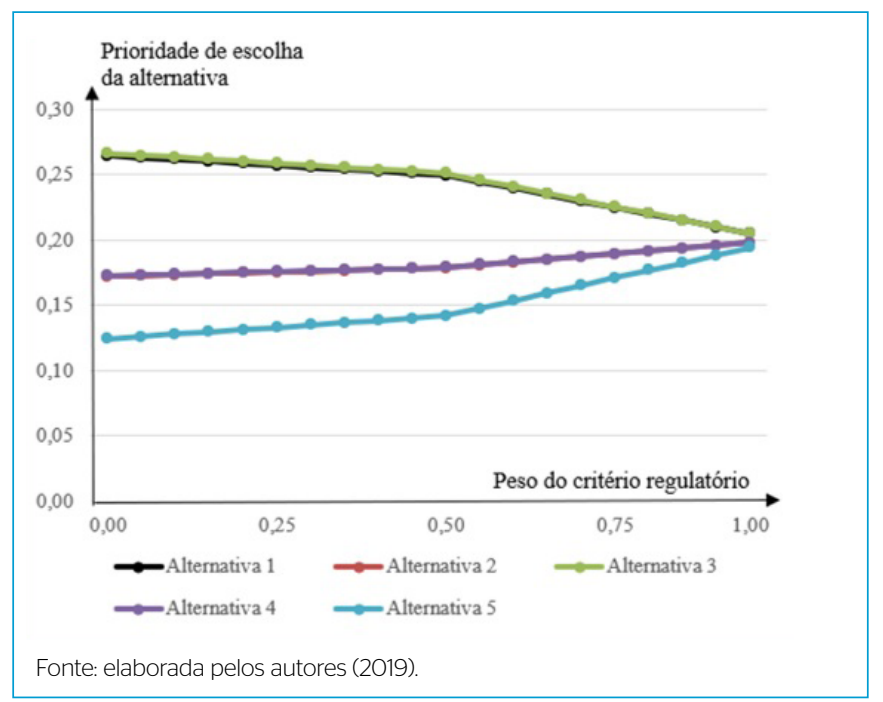

Figura 6 - Análise de sensibilidade do critério regulatório.
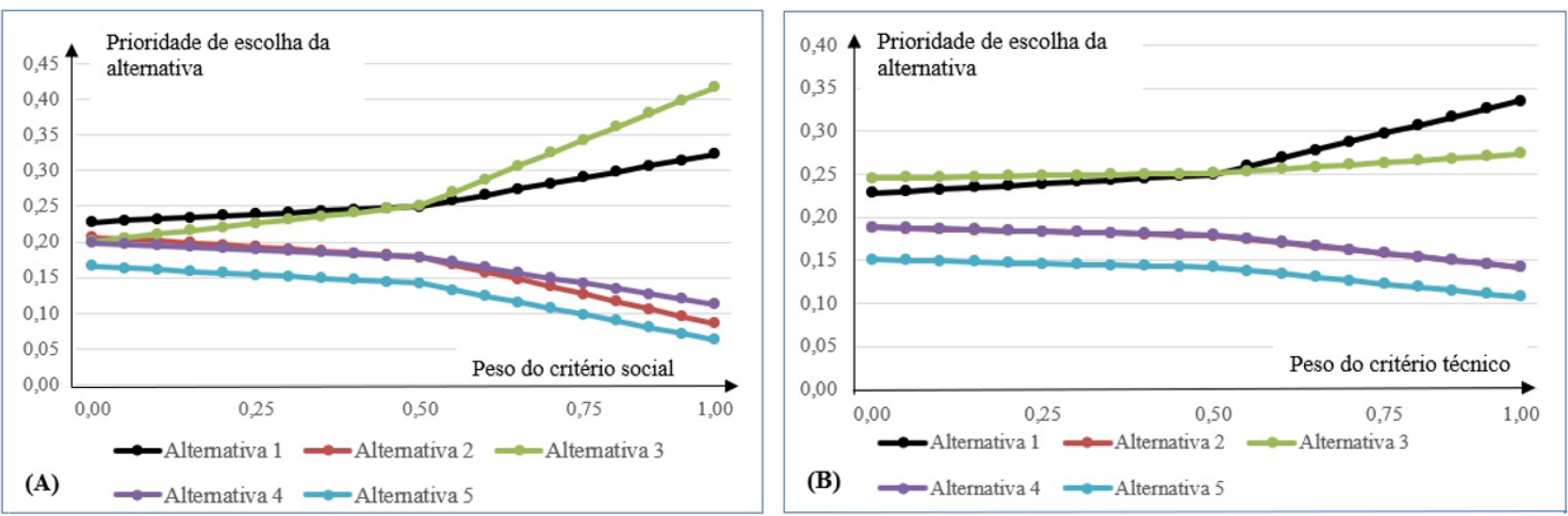

Fonte: elaborada pelos autores (2019).

Figura 5 - Análise de sensibilidade dos critérios social e técnico. 
de GEE evitada pela redução da demanda de energia produzida por combustíveis fósseis e custos indiretos à saúde) sejam considerados em trabalhos futuros. Ademais, enfatiza-se que a pesquisa considerou um conjunto de premissas em cenários ideais, nos quais a taxa de reciclagem é $100 \%$ e existe mercado consumidor para todo o fertilizante produzido e para toda a energia gerada nas diferentes alternativas. Entretanto, essas premissas apresentam limitações, como apresentado por Dai et al. (2019), Fang et al. (2018) e Madusanka et al. (2017). Nesse sentido, sugere-se que pesquisas futuras sejam realizadas para refinar os resultados deste estudo, utilizando percentuais mais precisos que levem em consideração, por exemplo, o mercado consumidor de fertilizante da região, gerando resultados mais assertivos em relação à renda gerada em cada alternativa.
Por fim, considerando-se o método aplicado, este estudo apresenta-se como uma contribuição acadêmica que pode ser utilizada por tomadores de decisões como base metodológica para planejar e definir ações de melhoria em sistemas de gestão de RS.

\section{CONTRIBUIÇÕES DOS AUTORES}

Müller, L. N. P. S.: Conceituação, Curadoria de Dados, Análise Formal, Investigação, Metodologia, Software, Escrita - Primeira Redação, Escrita Revisão e Edição. Arruda, J. B. F.: Conceituação, Metodologia, Administração do Projeto, Recursos, Supervisão, Visualização. Alcantara, R. L. C.: Escrita Revisão e Edição. Pereira, R. L.: Escrita - Revisão e Edição.

\section{REFERÊNCIAS}

ABBASI, S.A.; RAMASAMY, E.V. Biotechnological methods of pollution control. Hyderabad: Universities Press, 1999

ALI, M. Sustainable composting: case studies and guidelines for developing countries. Inglaterra: Water, Engineering and Development Centre, LouGhborough University, 2004.

ASSOCIAÇÃO BRASILEIRA DE EMPRESAS DE LIMPEZA PÚBLICA E RESIDUOS ESPECIAIS (ABRELPE). Panorama dos resíduos sólidos no Brasil 2011. São Paulo: Abrelpe, 2012.

ASSOCIAÇÃO BRASILEIRA DE EMPRESAS DE LIMPEZA PÚBLICA E RESÍDUOS ESPECIAIS (ABRELPE). Panorama dos resíduos sólidos no Brasil 2012. São Paulo: Abrelpe, 2013

ASSOCIAÇÃO BRASILEIRA DE EMPRESAS DE LIMPEZA PÚBLICA E RESÍDUOS ESPECIAIS (ABRELPE). Panorama dos resíduos sólidos no Brasil 2013. São Paulo: Abrelpe, 2014

ASSOCIAÇÃO BRASILEIRA DE EMPRESAS DE LIMPEZA PÚBLICA E RESÍDUOS ESPECIAIS (ABRELPE). Panorama dos resíduos sólidos no Brasil 2014. São Paulo: Abrelpe, 2015.

BEHROOZNIA, L.; SHARIFI, M.; ALIMARDANI, R.; MOUSAVI-AVVAL, S. $H$. Sustainability analysis of landfilling and composting-landfilling for municipal solid waste management in the north of Iran. Journal of Cleaner Production, v. 203, p. 1028-1038, 2018. https://doi.org/10.1016/j. jclepro.2018.08.307

BRASIL. Elementos para a organização da coleta seletiva e projeto dos galpões de triagem. Brasil: Ministério das Cidades, 2008

BRASIL. Lei no 12.305, de 2 de agosto de 2010. Institui a Política Nacional de Resíduos Sólidos; altera a Lei no 9.605, de 12 de fevereiro de 1998; e dá outras providências. Brasília, 2010.

BRASIL. Ministério de Minas e Energia. Anuário estatístico de energia elétrica 2015: ano base 2014. Rio de Janeiro: Empresa de Pesquisa Energética (EPE), 2015.

CENTRO DE APOIO OPERACIONAL ȦS PROMOTORIAS DE PROTEÇÃO AO MEIO AMBIENTE (CAOPMA). Unidades de triagem e compostagem de resíduos sólidos urbanos: apostila para a gestão municipal de resíduos sólidos urbanos. 2. ed. Curitiba: CAOPMA, 2013.

CHANG, N.B.; PIRES, A. Sustainable solid waste management: a systems engineering approach. Nova Jersey: IEEE Wiley, 2015.

CHESTER, M.; MARTIN, E.; SATHAYE, N. Energy, greenhouse gas, and cost reductions for municipal recycling systems. Environmental Science \& Technology, v. 42, n. 6, p. 2142-2149, 2008. https://doi.org/10.1021/es0713330

CHO, H.S.; MOON, H.S.; KIM, J.Y. Effect of quantity and composition of waste on the prediction of annual methane potential from landfills. Bioresource Technology, v. 109, p. 86-92, 2012. https://doi.org/10.1016/j. biortech.2012.01.026

CHRISTENSEN, T.H. Solid waste technology and management. Chichester: John Wiley \& Sons, 2011.

COMPROMISSO EMPRESARIAL PARA RECICLAGEM (CEMPRE). Artigos $e$ publicações: ficha técnica composto urbano. CEMPRE, 2016.

DAI, X.; ZHANG, S.; WATERHOUSE, G.IN.; FAN, H.; Al, S. Recyclable polyvinyl alcohol sponge containing flower-like layered double hydroxide microspheres for efficient removal of $\mathrm{As}(\mathrm{V})$ anions and anionic dyes from water. Journal of Hazardous Materials, v. 367, p. 286-292, 2019. https://doi. org/10.1016/j.jhazmat.2018.12.092

EUROPEAN COMMISSION. Integrated pollution prevention and control: reference document on best available techniques for the waste treatment industries. European Commission, 2006.

FANG, S.; YANG, W.; CAO, H.; SONG, Q.; ZHANG, Y.; SUN, Z. Evaluation on end-of-life LEDs by understanding the criticality and recyclability for metals recycling. Journal of Cleaner Production, v. 182, p. 624-633, 2018. https://doi. org/10.1016/j.jclepro.2018.01.260

FEHR, M. O alvo final é o lixo zero. Caminhos da Geografia, v. 11, n. 35, p. $54-62,2010$

FUNDAÇÃO DE APOIO AO DESENVOLVIMENTO DA UNIVERSIDADE FEDERAL DE PERNAMBUCO (FADE). Análise das diversas tecnologias de tratamento e disposição final de resíduos sólidos urbanos no Brasil, Europa, 
Estados Unidos e Japão. Grupo de resíduos sólidos. Pernambuco: UFPE/ BNDES, jul. 2014.

FUNDAÇÃO ESTADUAL DO MEIO AMBIENTE (FEAM). Aproveitamento energético de resíduos sólidos urbanos: guia de orientações para governos municipais de Minas Gerais. Belo Horizonte: Fundação Estadual do Meio Ambiente, 2012. 294 p.

GOVERNOS LOCAIS PELA SUSTENTABILIDADE, SECRETARIADO PARA AMÉRICA LATINA E CARIBE, ESCRITÓRIO DE PROJETOS NO BRASIL (ICLEI). Manual para aproveitamento de biogás: efluentes urbanos. São Paulo: ICLEI, 2010. v. 2.

HARTMANN, H.; AHRING, B.K. Anaerobic digestion of the organic fraction of municipal solid waste: influence of co-digestion with manure. Water Research, v. 39, n. 8, p. 1543-1552, 2005. https://doi.org/10.1016/j. watres.2005.02.001

HENRIQUES, R.M. Aproveitamento energético dos resíduos sólidos urbanos: uma abordagem tecnológica. 203f. Dissertação (Mestrado em Planejamento Energético) - Instituto Alberto Luiz Coimbra de PósGraduação e Pesquisa de Engenharia (COPPE), Universidade Federal do Rio de Janeiro, Rio de Janeiro, 2004

INÁCIO, C.T.; BETTIO, D.B.B.; MILLER, P.R.M. O papel da compostagem de resíduos orgânicos urbanos na mitigação de emissões de metano. Rio de Janeiro: Embrapa Solo, 2010.

INSTITUTE FOR LOCAL SELF-RELIANCE (ILSR). Waste to wealth: recycling means business. Washington, D.C.: ILSR, 1997. Disponível em: https://ilsr.org/ recycling-means-business/. Acesso em: 18 maio 2016.

INSTITUTO BRASILEIRO DE GEOGRAFIA E ESTATÍSTICA (IBGE). Estimativas populacionais para os municípios e para as unidades da federação brasileiras em 1.07.2015. Brasil: IBGE, 2015. Disponível em: ftp:// ftp.ibge.gov.br/Estimativas_de_Populacao/Estimativas_2015/estimativa_ dou_2015_20150915.xls. Acesso em: 5 out. 2015.

JOHNKE, B. Emissions from waste incineration: good practice guidance and uncertainty management in national greenhouse gas inventories. Intergovernmental Panel on Climate Change, p. 455-468, 2002

KALYANI, K.A.; PANDEY, K.K. Waste to energy status in India: a short review. Renewable and Sustainable Energy Reviews, v. 31, p. 113-120, 2014. https://doi. org/10.1016/j.rser.2013.11.020

KARANJEKAR, R.V;; BHATT, A.; ALTOUQUI, S.; JANGIKHATOONABAD, N.; DURAI, V.; SATTLER, M.L.; HOSSAIN, M.D.S.; CHEN, V. Estimating methane emissions from landfills based on rainfall, ambient temperature, and waste composition: the CLEEN model. Waste Management, v. 46, p. 389-398, 2015. https://doi.org/10.1016/j.wasman.2015.07.030

KHAN, M.M.U.H.; JAIN, S.; VAEZI, M.; KUMAR, A. Development of a decision model for the techno-economic assessment of municipal solid waste utilization pathways. Waste Management, v. 48, p. 548-564, 2016. https://doi. org/10.1016/j.wasman.2015.10.016

KING, M.F; GUTBERLET, J. Contribution of cooperative sector recycling to greenhouse gas emissions reduction: a case study of Ribeirão Pires, Brazil. Waste Management, v. 33, n. 12, p. 2771-2780, 2013. https://doi.org/10.1016/j. wasman.2013.07.031

LOMBARDI, L.; CARNEVALE, E.; CORTI, A. A review of technologies and performances of thermal treatment systems for energy recovery from waste. Waste Management, v. 37, p. 26-44, 2015. https://doi.org/10.1016/j. wasman.2014.11.010

MADUSANKA, K.H.P.; MATSUTO, T.; TOJO, Y.; HWANG, I. Questionnaire and onsite survey on municipal solid waste composting in Sri Lanka. Journal of Material Cycles and Waste Management, v. 19, p. 804-814, 2017. https://doi org/10.1007/s10163-016-0479-y

MERSONI, C.; REICHERT, G.A. Comparação de cenários de tratamento de resíduos sólidos urbanos por meio da técnica da Avaliação do Ciclo de Vida: o caso do município de Garibaldi, RS. Engenharia Sanitária e Ambiental, v. 22, n. 5, p. 863-875, 2017. https://doi.org/10.1590/s1413-41522017150351

MIA, S.; UDDINE, E.; KADER, A.; AHSAN, A.; MANNAN, M.A.; HOSSAIN, M.M. SOLAIMAN, Z.M. Pyrolysis and co-composting of municipal organic waste in Bangladesh: A quantitative estimate of recyclable nutrients, greenhouse gas emissions, and economic benefits. Waste Management, v. 75, p. 503513, 2018. https://doi.org/10.1016/j.wasman.2018.01.038

MOLETTA, R.; VERRIER, D.; ALBAGNAC, G. Dynamic modelling of anaerobic digestion. Water Research, v. 2O, n. 4, p. 427-434, 1986. https://doi. org/10.1016/0043-1354(86)90189-2

NOBRE, C.A.; REID, J.; VEIGA, A.P.S. Fundamentos científicos das mudanças Climáticas. São José dos Campos: Rede Clima/Inpe, 2012. 44 p.

QAZI, W.A.; ABUSHAMMALA, M.F.M.; AZAM, M.H. Multi-criteria decision analysis of waste-to-energy technologies for municipal solid waste management in Sultanate of Oman. Waste Management and Research, v. 36, n. 7, p. 594-605, 2018. https://doi.org/10.1177/0734242X18777800

REICHERT, G.A.; MENDES, C.A.B. Avaliação do ciclo de vida e apoio à decisão em gerenciamento integrado e sustentável de resíduos sólidos urbanos. Engenharia Sanitária e Ambiental, v. 19, n. 3, p. 301-313, 2014. https:// doi.org/10.1590/S1413-41522014019000001145

SAATY, T.L. The analytic hierarchy process and health care problems. Nova York: McGraw-Hill, 1980.

SECRETARIA DE MEIO AMBIENTE, AGRICULTURA E SERVIÇOS PÚBLICOS (SEMASP). Plano de gestão integrada de resíduos sólidos urbanos - PGIRSU. Juazeiro do Norte: Semasp, 2013.

SILVA, E.R. Estimativa do potencial energético dos resíduos sólidos urbanos por diferentes rotas de tratamento. 204f. Tese (Pós-graduação em Energia) - Universidade Federal do ABC, Santo André, 2015.

SILVA, E.R. Modelagem matemática da produção e transporte de biogás em aterros sanitários. 82f. Dissertação (Mestrado em Energia) - Universidade Federal do ABC, Santo André, 2010.

SIQUEIRA, T.M.O.; ASSAD, M.L.R.C.L. Compostagem de resíduos sólidos urbanos no Estado de São Paulo (Brasil). Ambiente e Sociedade, São Paulo, v. 18, n. 4, p. 243-264, 2015. https://doi.org/10.1590/18094422ASOC1243V1842015

SOLTANI, A.; HEWAGE, K.; REZA, B.; SADIQ, R. Multiple stakeholders in multi-criteria decision-making in the context of municipal solid waste management: a review. Waste Management, v. 35, p. 318-328, 2015. https:// doi.org/10.1016/j.wasman.2014.09.010

THAKUR, P.; GANGULY, R.; DHULIA, A. Occupational Health Hazard Exposure among municipal solid waste workers in Himachal Pradesh, India. Waste Management, v. 78, p. 483-489, 2018. https://doi.org/10.1016/j. wasman.2018.06.020 
THEMELIS, N.J.; BARRIGA M.E.D.; ESTEVEZ, P.; VELASCO, M.G. Guidebook for the application of waste to energy technologies in Latin America and the Caribbean. Colúmbia: Earth Engineering Center, Columbia University, 2013.

UNITED STATES ENVIRONMENTAL PROTECTION AGENCY (USEPA). Landfill gas emissions model v.3.02. Estados Unidos: USEPA, 2005. Disponível em: http://www.epa.gov/ttn/catc/dir1/landgem-v302.xls. Acesso em: 9 dez. 2015.

WORLD WIDE FUND FOR NATURE BRASIL (WWF BRASIL). Guia para a compostagem: orientação para o aproveitamento de resíduos orgânicos em sistemas de pequeno e médio porte. Brasília: WWF Brasil, 2015.
YANG, D.: XU, L.; GAO, X.; GUO, X.; HUANG, N. Inventories and reduction scenarios of urban waste-related greenhouse gas emissions for management potential. Science of the Total Environment, v. 626, p. 727-736, 2018. https://doi.org/10.1016/j.scitotenv.2018.01.110

YAP, H.Y; NIXON, J.D. A multi-criteria analysis of options for energy recovery from municipal solid waste in India and the UK. Waste Management, v. 46, p. 265-271, 2015. https://doi.org/10.1016/j.wasman.2015.08.002

YOUNES, M.K.; NOPIAH, Z.M.; BASRI, N.E.A.; BASRI, H.; ABUSHAMMALA, M.F.M.; YOUNES, M.Y. Landfill area estimation based on integrated waste disposal options and solid waste forecasting using modified ANFIS model. Waste Management, v. 55, p. 3-11, 2016. https://doi.org/10.1016/j. wasman.2015.10.020 